\title{
The Study on Gray-hierarchy Analysis in Risk Management of Subway Construction
}

\author{
Wentao Wang ${ }^{1, \text { a }}$, Zengrong Liu ${ }^{2, b}$ \\ ${ }^{1}$ School of Civil Engineering, Xi'an University of Architecture and Technology, Xi'an Shanxi, China \\ ${ }^{2}$ School of Civil Engineering, Xi'an University of Architecture and Technology, Xi'an Shanxi, China \\ aWwt197796@163.com, bIzr@nwpu.edu.cn
}

Keywords: subway construction; risk management; safety evaluation system; gray-hierarchy evaluation.

\begin{abstract}
The factors of risk management have been analyzed and evaluated in subway construction by adopting gray-hierarchy analysis. According to the characteristics of the subway construction, analyze the risk factors of the surrounding environments in the construction period, and establish the gray-hierarchy model of risk analysis. Sort the risk factors by using the gray-hierarchy analysis, and whiten gray system of engineering risk whose information are incomplete by using gray whiten weight function in gray theory. It is proved that the model is qualitative analysis by the mathematical method into quantitative analysis. Combining with the subway station engineering construction case in Xi'an, draw the evaluation value of engineering risk in subway construction.
\end{abstract}

\section{Introduction}

In recent years, with the rapid development of urban subway and the national economy, the subway is known as the best public transport. Due to the large number of uncertainty in the construction process, and the risk is mainly caused by an uncertain event or activity. Therefore, application of rigorous scientific methods in risk analysis about the subway construction help to reduce or prevent the occurrence of accidents, control the project cost, strengthen the construction process safety, and environmental protection.

By analyzing the characteristics of subway construction and the actual situation, safety evaluation system on subway construction was established. The theory of Grey System and AHP were applied to construct a Grey Hierarchy Model for risk analysis. By using whiten function gray theory, white the incomplete engineering risk and qualitative analysis was transformed to quantitative analysis through mathematical method. Finally, judge the index value of the security level.

\section{Build the safety evaluation system of pit construction on subway}

To ensure the successful implementation of the subway construction and minimal risk of loss, a risk assessment system on subway construction was established in this paper in order to control and avoid the risks. Safety evaluation system of pit construction on subway is consisted of two parts: the pit structure and the surrounding environment. These two parts are the direct factors of pit construction safely, and both can be reflected by monitoring data. Therefore, the evaluation system was established by monitoring data of pit:

Table 1 safety evaluation system of subway construction

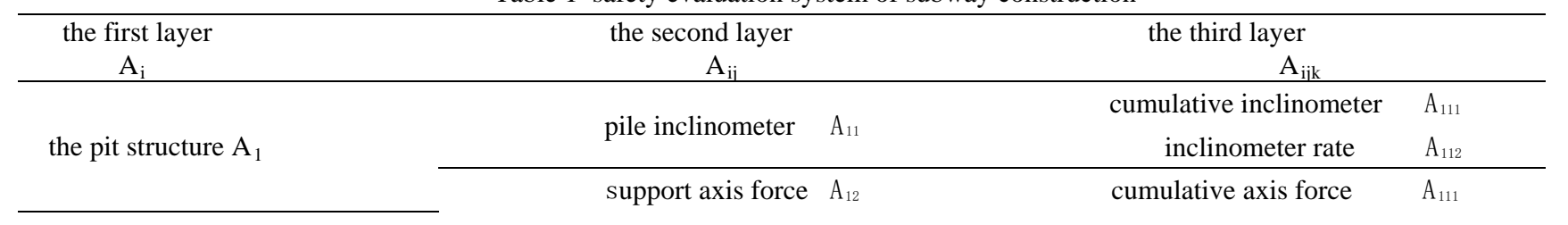




\begin{tabular}{|c|c|c|c|}
\hline & column settlement $A_{13}$ & $\begin{array}{c}\text { cumulative inclinometer } \\
\text { inclinometer rate }\end{array}$ & $\begin{array}{l}\mathrm{A}_{131} \\
\mathrm{~A}_{132} \\
\end{array}$ \\
\hline & surface subsidence $\quad A_{14}$ & $\begin{array}{c}\text { cumulative inclinometer } \\
\text { inclinometer rate }\end{array}$ & $\begin{array}{l}\mathrm{A}_{141} \\
\mathrm{~A}_{142} \\
\end{array}$ \\
\hline & surface water outside the pit $A_{15}$ & $\begin{array}{c}\text { cumulative inclinometer } \\
\text { inclinometer rate }\end{array}$ & $\begin{array}{l}A_{151} \\
A_{152} \\
\end{array}$ \\
\hline & horizontal displacement $A_{16}$ & $\begin{array}{c}\text { cumulative inclinometer } \\
\text { inclinometer rate }\end{array}$ & $\begin{array}{l}A_{161} \\
A_{162} \\
\end{array}$ \\
\hline \multirow{3}{*}{ surrounding environment $A_{2}$} & buildings settlement $A_{21}$ & $\begin{array}{c}\text { cumulative inclinometer } \\
\text { inclinometer rate }\end{array}$ & $\begin{array}{l}A_{211} \\
A_{212} \\
\end{array}$ \\
\hline & pipeline settlement $\quad A_{22}$ & $\begin{array}{c}\text { cumulative inclinometer } \\
\text { inclinometer rate }\end{array}$ & $\begin{array}{l}\mathrm{A}_{221} \\
\mathrm{~A}_{222}\end{array}$ \\
\hline & pier settlement & $\begin{array}{c}\text { cumulative inclinometer } \\
\text { inclinometer rate }\end{array}$ & $\begin{array}{l}\mathrm{A}_{231} \\
\mathrm{~A}_{232}\end{array}$ \\
\hline
\end{tabular}

\section{Build the grey AHP evaluation model}

Ensure the index weight by AHP. In the index system, the more important the indexes, the bigger of weight value are entitled. Firstly, the researchable question was disintegrated into constituent elements. By comparing between any two, to ensure the relative importance of each elements and build the judgment matrix. Secondly, come up with weight by solution matrix eigenvalue. Finally, check and judge whether the judgment matrix meets the consistency, otherwise, it is necessary to modify the judgment matrix until it meets the requirements.

Ensure the sample matrix of evaluation index. Establishing the risk assessment system, it is necessary transform qualitative indicators into quantitative indicators. Because there are many types of risk in subway construction and different degrees of impact as well, the risk was classified into 5 levels that highest risk, high risk, general risk, the more low-risk and low risk, and entitled with $1,2,3,4,5$. When the level of risk index is between the two appropriate level, the score is an average of two adjacent corresponding assignment, namely, 1.5,2.5,3.5,4.5 points.

According to risk level has been formulated, $n$ experts were organized to fill in experts rate tables to score the risk levels. Then, sample matrix $D$ of evaluation of construction risk on this projects is obtained, which there are $p$ evaluation factors and the last evaluation factor has $q$ evaluation indexes.

$$
D=\left[\begin{array}{cccc}
d_{111} & d_{112} & \cdots & d_{11 n} \\
d_{121} & d_{122} & \cdots & d_{12 n} \\
& & \vdots & \\
d_{211} & d_{212} & \cdots & d_{21 n} \\
& & \vdots & \\
d_{p q 1} & d_{p q 2} & \cdots & d_{p q n}
\end{array}\right]
$$

Fig.1 scoring sample matrix

Ensure the evaluation gray type and whiten function of index system. In order to reflect the impact of risk objectively, it is usually need to determine evaluation gray type of project risk, namely, ensure the evaluation gray grade, gray numbers and their weight functions. The gray type was divided into five grades, which are low, lower, general, higher, highest. They are expressed by $e(e=1,2$, $3,4,5)$.In this paper, the weight function was adopted straight, $X_{1}=1, X_{2}=2, X_{3}=3$, $X_{4}=4, X_{5}=5$. And the gray numbers corresponding to the weight function are as followings:

(1) low risk $(e=1)$, gray number $\otimes_{1} \in[0,1,2]$, the weight function $f_{1}$ is as follows: 


$$
f_{1}\left(d_{p q n}\right)=\left\{\begin{array}{cc}
1 & d_{p q n} \in[0,1] \\
2-d_{p q n} & d_{p q n} \in[1,2] \\
0 & d_{p q n} \notin[0,2]
\end{array}\right.
$$

(2) lower risk $(e=2)$,gray number $\otimes_{2} \in[0,2,4]$, the weight function $f_{2}$ is as follows:

$$
f_{2}\left(d_{p q n}\right)=\left\{\begin{array}{cc}
d_{p q n} / 2 & d_{p q n} \in[0,2] \\
\left(4-d_{p q n}\right) / 2 & d_{p q n} \in[2,4] \\
0 & d_{p q n} \notin[0,4]
\end{array}\right.
$$

(3) general ( $e=3$ ),gray number $\otimes_{3} \in[0,3,6]$,the weight function $f_{3}$ is as follows:

$$
f_{3}\left(d_{p q n}\right)=\left\{\begin{array}{cc}
d_{p q n} / 3 & d_{p q n} \in[0,3] \\
\left(6-d_{p q n}\right) / 3 & d_{p q n} \in[3,6] \\
0 & d_{p q n} \notin[0,6]
\end{array}\right.
$$

(4) higher ( $e=4)$,gray number $\otimes_{4} \in[0,4,8]$,the weight function $f_{4}$ is as follows:

$$
f_{4}\left(d_{p q n}\right)=\left\{\begin{array}{cc}
d_{p q n} / 4 & d_{p q n} \in[0,8] \\
\left(8-d_{p q n}\right) / 4 & d_{p q n} \in[4,8] \\
0 & d_{p q n} \notin[0,8]
\end{array}\right.
$$

(5) highest ( $e=5$ ),gray number $\otimes_{5} \in[0,5,10]$,the weight function $f_{5}$ is as follows:

$$
f_{5}\left(d_{p q n}\right)=\left\{\begin{array}{cc}
d_{p q n} / 5 & d_{p q n} \in[0,5] \\
\left(10-d_{p q n}\right) / 5 & d_{p q n} \in[5,10] \\
0 & d_{p q n} \notin[0,10]
\end{array}\right.
$$

Ensure the gray evaluation coefficient. For risk evaluation index $A_{i j}$ of engineering, the gray evaluation coefficient $M_{i j e}$ and $M_{i j}$ are as follows:

$$
\begin{aligned}
& M_{i j e}=\sum_{k=1}^{m} f_{e}\left(d_{p q n}\right) \\
& M_{i j}=\sum_{e=1}^{5} M_{i j e}
\end{aligned}
$$


Calculate gray evaluation weight vector and matrix. The gray evaluation weight $r_{i j e}$ is as follows. For 5 gray evaluation weight $r_{i j}$ of gray types, gray evaluation matrix $R_{i}$ can be obtained, in which $r_{i j}=\left|r_{i j 1}, r_{i j 2}, r_{i j 3}, r_{i j 4}, r_{i j 5}\right|$.

$$
r_{i j e}=M_{i j e} / M_{i j}
$$

Total evaluation of the project Evaluate the second layer $A_{i j}$, and the results $B_{i}$ can be achieved using the following formula:

$$
B_{i}=A_{i} \cdot R_{i}
$$

Evaluate the first layer $U_{i}$, and the results $B$ can be achieved using the following formula:

$$
B=A \cdot B_{i}
$$

Evaluate the total target of risk project. Because the comprehensive evaluation result $C$ is a vector, only do further processing can clear the value of risk. Assignment vector $C$ is needed according to evaluation gray type. The evaluation value of total target is as follows:

$$
Z=B \cdot C^{T}
$$

Ensure the risk level according to the value of $Z$. Appropriate measures are adopted to deal with and control risks.

\section{Empirical application by using the grey AHP}

Build risk index system of subway construction. According to the hierarchical model and the principles of risk index system, establish the system combined with characteristics of the projects is

\begin{tabular}{|c|c|c|c|c|c|c|}
\hline factor & $\begin{array}{c}\text { pile } \\
\text { inclinometer }\end{array}$ & $\begin{array}{c}\text { support } \\
\text { axis force }\end{array}$ & $\begin{array}{c}\text { column } \\
\text { settlement }\end{array}$ & $\begin{array}{c}\text { surface } \\
\text { subsidence }\end{array}$ & $\begin{array}{c}\text { surface water } \\
\text { outside pit }\end{array}$ & $\begin{array}{c}\text { horizontal } \\
\text { displacement }\end{array}$ \\
\hline pile inclinometer & 1 & 5 & 3 & 3 & 4 & 4 \\
\hline support axis force & $1 / 5$ & 1 & $3 / 7$ & $4 / 7$ & $4 / 7$ & $5 / 7$ \\
\hline column settlement & $1 / 3$ & $7 / 3$ & 1 & 2 & 3 & $5 / 3$ \\
\hline surface subsidence & $1 / 3$ & $7 / 4$ & $1 / 2$ & 1 & 3 & $5 / 3$ \\
\hline surface water outside pit & $1 / 4$ & $7 / 4$ & $1 / 3$ & $1 / 3$ & 1 & $2 / 3$ \\
\hline horizontal displacement & $1 / 4$ & $7 / 5$ & $3 / 5$ & $3 / 5$ & $3 / 2$ & 1 \\
\hline
\end{tabular}
shown in Table 1.

Ensure the weight. Based on 1-9 scale, compare any of two indexes in table1 to come up with judgment matrix, then calculate the weight and consistency which were shown in Table 2-3.

Notes: $\lambda_{\max }=5.2012 \quad C I=0.0141 \quad C I / R I=0.0243<0.1$ 


\begin{tabular}{cccccc}
\hline factor & $\begin{array}{c}\text { buildings } \\
\text { settlement }\end{array}$ & $\begin{array}{c}\text { pipeline } \\
\text { settlement }\end{array}$ & pier settlement & W & consistency \\
\hline buildings settlement & 1 & 4 & 5 & 0.6878 & $\lambda_{\text {max }}=3.0037$ \\
pipeline settlement & $1 / 4$ & 1 & $6 / 4=0.0019$ & $C I / R I=0.0032$ \\
pier settlement & $1 / 5$ & $4 / 6$ & 1 & 0.1827 & Fulfil requirements \\
\hline
\end{tabular}

According to the engineering characteristics of subway construction, the first layer weights were $A=\left(\begin{array}{ll}a_{1} & a_{2}\end{array}\right)=(0.6,0.4)$. As $C I / R I$ were less than 1 , it can be considered that the judgment matrix is consistent. Therefore, the weights of second layer about the pit structure and surrounding

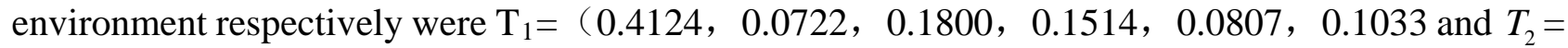
( $0.6878,0.1827,0.1295)$. The $A_{i j}$ and $A_{i j k}$ were as follows:

$$
\begin{aligned}
& A_{i}=\left(\begin{array}{ll}
0.6 & 0.4
\end{array}\right)\left(\begin{array}{cc}
T_{1} & 0 \\
0 & T_{2}
\end{array}\right)=\left(a_{11}, a_{12}, a_{13}, a_{14}, a_{15}, a_{16}, a_{21}, a_{22}, a_{23}\right) \\
&=(0.2474,0.0433,0.1080,0.0908,0.0485,0.0620,0.2751,0.0731,0.0518) ; \\
& A_{11}=(0.2,0.8) ; A_{12}=(1.0) ; A_{13}=(0.2,0.8) ; A_{14}=(0.2,0.8) ; A_{15}=(0.2,0.8) ; A_{16}= \\
&(0.2,0.8) ; A_{21}=(0.2,0.8) ; A_{22}=(0.2,0.8) ; A_{23}=(0.2,0.8) 。
\end{aligned}
$$

Ensure the scoring matrix. Based on rating criteria(1-5score), $\mathrm{A}_{\mathrm{ijk}}$ were scored by 5 technical staffs. The results were as follows:

$$
D=\left[\begin{array}{ccccc}
3 & 2.5 & 2 & 2.5 & 2 \\
3.5 & 3 & 3 & 3.5 & 4 \\
2.5 & 3 & 2.5 & 2 & 2.5 \\
4 & 3 & 3.5 & 3 & 3.5 \\
2 & 2.5 & 3 & 2 & 2 \\
3.5 & 3 & 3 & 3.5 & 4 \\
3 & 3 & 3.5 & 2.5 & 3 \\
3 & 3 & 2.5 & 2.5 & 3.5 \\
4 & 3 & 3.5 & 4 & 3.5 \\
3 & 3.5 & 3 & 3.5 & 4 \\
2.5 & 2.5 & 2 & 2 & 2.5 \\
2 & 2 & 2.5 & 2.5 & 2 \\
2 & 2 & 2 & 2 & 2.5 \\
2 & 1 & 1.5 & 1 & 1 \\
2.5 & 1 & 1.5 & 1.5 & 1 \\
2 & 1 & 1.5 & 1.5 & 1 \\
2.5 & 1 & 2 & 1.5 & 1.5
\end{array}\right]
$$

According to formula 1, $M_{i j e}$ were as follows:

$$
\begin{aligned}
& e=1: M_{111}=f_{1}\left(d_{111}\right)+f_{1}\left(d_{112}\right)+f_{1}\left(d_{113}\right)+f_{1}\left(d_{114}\right)+f_{1}\left(d_{115}\right)=0 \\
& e=2: M_{112}=5_{;} e=3: \quad M_{113}=4_{;} e=4: M_{114}=3 ; e=5: M_{115}=2.4 .
\end{aligned}
$$

According to formula 2, $M_{11}$ is: $M_{11}=M_{111}+M_{112}+M_{113}+M_{114}+M_{115}=14.4$

According to formula3:

$e=1: \quad r_{111}=0 ; \quad e=2: \quad r_{112}=0.3472 ; \quad e=3: \quad r_{113}=0.2778 ; \quad e=4: \quad r_{114}=0.2083$ 
$e=5: \quad r_{115}=0.1667 ; r_{11}=\left(r_{111}, r_{112}, r_{113}, r_{114}, r_{115}\right)=(0,0.3472,0.2778,0.2083,0.1667)$

According to the same calculation method, the total evaluation coefficient of other indexes can be achieved. The Grey evaluation matrixes were as follows:

$$
\begin{aligned}
& R_{1}=\left[\begin{array}{lllll}
0 & 0.3427 & 0.2778 & 0.2083 & 0.1667 \\
0 & 0.1112 & 0.3214 & 0.3152 & 0.2522
\end{array}\right] \quad R_{2}=\left[\begin{array}{lllll}
0 & 0.2770 & 0.3076 & 0.2308 & 0.1846
\end{array}\right] \\
& R_{3}=\left[\begin{array}{lllll}
0 & 0.1112 & 0.3214 & 0.3152 & 0.2522 \\
0 & 0.3206 & 0.2891 & 0.2168 & 0.1735
\end{array}\right] \quad R_{4}=\left[\begin{array}{lllll}
0 & 0.1112 & 0.3214 & 0.3152 & 0.2522 \\
0 & 0.2346 & 0.3129 & 0.2514 & 0.2011
\end{array}\right] \\
& R_{5}=\left[\begin{array}{lllll}
0 & 0.1996 & 0.3267 & 0.2632 & 0.2105 \\
0 & 0.0600 & 0.2265 & 0.3698 & 0.3437
\end{array}\right] \quad R_{6}=\left[\begin{array}{lllll}
0 & 0.1112 & 0.3214 & 0.3152 & 0.2522 \\
0 & 0.3206 & 0.2891 & 0.2168 & 0.1735
\end{array}\right] \\
& R_{7}=\left[\begin{array}{lllll}
0 & 0.3431 & 0.2795 & 0.2097 & 0.1677 \\
0 & 0.3661 & 0.2698 & 0.2023 & 0.1618
\end{array}\right] \quad R_{8}=\left[\begin{array}{lllll}
0.2956 & 0.2744 & 0.1830 & 0.1372 & 0.1098 \\
0.2474 & 0.2680 & 0.2063 & 0.1546 & 0.1237
\end{array}\right] \\
& R_{9}=\left[\begin{array}{lllll}
0.2503 & 0.2927 & 0.1947 & 0.1460 & 0.1168 \\
0.1612 & 0.3022 & 0.2283 & 0.1713 & 0.1370
\end{array}\right]
\end{aligned}
$$

Calculate the comprehensive evaluation value. According to formula4, $\mathrm{B}_{\mathrm{i}}$ can be obtained.

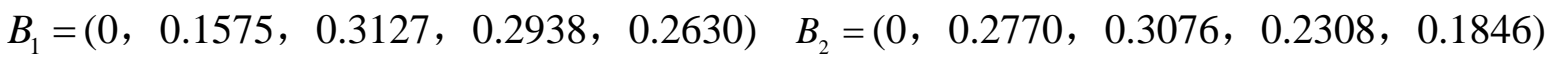

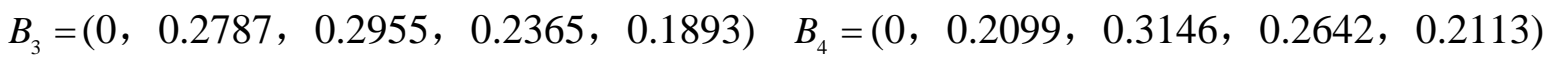

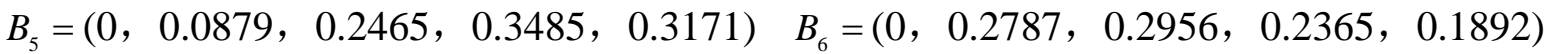

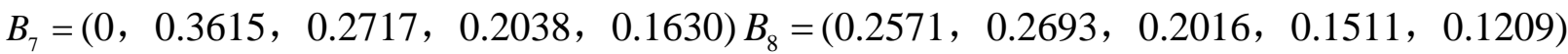

$$
\begin{aligned}
& B_{9}=\left(\begin{array}{llll}
0.1790,0.3003, & 0.2216,0.1661,0.1330
\end{array}\right)
\end{aligned}
$$

According to formula5, $B$ can be achieved. $B=(0.2133,0.2255,0.2931,0.2584,0.0097)$. The grey level should be expressed by $C=(1,2,3,4,5)$. According to formula $6, Z=2.6257$, which the risk is acceptable based on risk acceptance criteria. During the construction, it need strengthen prevention and corresponding warning measures.

\section{Summary}

In this paper, pit safety evaluation system was established by using grey AHP. Then build the risk analysis of grey AHP model, and it is proved that the model can be transformed into quantitative analysis by the mathematical method. From the evaluation result, it can be seen that the evaluation system is reasonable and can provide reference for similar projects.

\section{References}

[1] C.G. Zhong, H.X. Liu. Risk analysis and countermeasures of deep excavation: Construction Supervision, Vol. (6) (2009), p.64-66

[2] H.James, A.Boykin.The evaluation of reaestate. Rogenssprentiee Hall. Ine(1993)

[3] H.W. Gao, W.M. TONG. A fieldbus evaluation method combining analytic hierarchy process and grey relational analysis:Journal of Harbin Engineering University, Vol. 29(12)(2008), p.1309-1314

[4] X.D.Li. Hierarchy-gray relevancy analysis technique and its applications in the optimization of the sewage treatment programs:Taiyaun: Taiyuan University of Technology(2006), p.64-71

[5] N.C. Robert. Software Engineering Risk Analysis and Management. New York: MeGraw-Hill Book Company(1989), p.97-99 